delayed in the smallest neonates. For all consecutive postnatal observations, Jaffe always resulted in higher Scr compared to the enzymatic technique, but the differences in median values between both techniques $(0.1-0.26 \mathrm{mg} / \mathrm{dl}$, equal to $8.8-23 \mu \mathrm{mol} / \mathrm{l})$, were not a fixed value.

Conclusions When using Scr to estimate renal function in neonates, clinicians should in addition to postnatal changes and other covariates of renal function, also consider the technique applied. There is no fixed conversion factor to correct for differences between both techniques.

1. Allegaert, J Matern Fetal Neonatal Med DOI 10.3109/14767058.2012.657277.

2. Kuppens, J Matern Fetal Neonatal Med DOI 10.3109/14767058.2011.602144.

3. Bueva, Pediatr Res 1994

\section{NEWBORN AND ADULT MONOCYTES SHOW DIFFERENT INFLAMMATORY RESPONSES TO BACTERIAL INFECTION: POTENTIAL ROLE OF MAPK INHIBITION}

doi:10.1136/archdischild-2012-302724.1337

EM Speer, AJ Chander. Pediatrics, Stony Brook University, Stony Brook, NY, USA

Background and Aims The neonatal inflammatory response is associated with adverse outcomes like chronic lung disease. Recent studies suggested that newborn innate immune responses differ from adults. We aim to compare the expression of inflammatory cytokines between newborn and adult monocytes, and to investigate the mechanisms underlying the differential response.

Methods Purified monocytes from 15 healthy term newborns (C-section, no labor or chorioamnionitis) and 15 healthy adults (no infection), were cultured (90min) and stimulated without or with $0.1 \mathrm{ng} / \mathrm{ml}$ or $10 \mathrm{ng} / \mathrm{ml}$ LPS for 4 or 24 hours. Cells were harvested and RNA extracted. mRNA expression was determined with real-time PCR and normalized to $\beta 2$-microglobulin as housekeeping gene. Results were analyzed by ANOVA and Students t-test with $p \leq 0.05$ considered significant.

Results Results are discussed in comparison to control values. Newborn monocytes showed increased IL6 $(0.1 \mathrm{ng} / \mathrm{ml}$ or $10 \mathrm{ng} / \mathrm{ml}$ LPS) and TNF $\alpha(0.1 \mathrm{ng} / \mathrm{ml}$ LPS) expression after $4 \mathrm{~h}$, whereas IL10mRNA was lower after $4 \mathrm{~h}$ and $24 \mathrm{~h}$ LPS compared to adults. LPS-stimulation increased NFKBp65 expression in adults but not in newborns at $24 \mathrm{~h}$. IKB $\alpha$ and Toll-interacting protein were comparable between groups. IRAK3 (TLR4-pathway regulator) was elevated in newborns at 4 and $24 \mathrm{~h}$ with LPS-stimulation, but only at $24 \mathrm{~h}$ in adults. Dual specificity phosphatase 1 (DUSP1) was significantly lower in newborn monocytes compared to adults after 24h LPS at both concentrations.

Conclusions Newborn compared to adult monocytes show increased expression of inflammatory cytokines. Diminished upregulation of DUSP1 (negative regulator of MAPK-pathway) might explain the enhanced pro-inflammatory profile of newborn compared to adult monocytes after microbial stimulation.

\section{HIGH PROPORTION OF INTESTINAL ESBL COLONIZATION AMONG INFANTS AT A NEONATAL INTENSIVE CARE UNIT IN A TERTIARY HOSPITAL IN ECUADOR}

doi:10.1136/archdischild-2012-302724.1338

IV Nordberg, ${ }^{2} \mathrm{~A}$ Quizphe, ${ }^{3} \mathrm{C}$ Giske, ${ }^{3} \mathrm{~A}$ Iversen, ${ }^{2} \mathrm{~T}$ Galindo, ${ }^{2} \mathrm{E}$ Ochoa, 'L Navér. ${ }^{1}$ Department of Clinical Science, Intervention and Technology (CLINTEC)/Division of Paediatrics, Karolinska Institute, Karolinska University Hospital, Stockholm, Sweden; 2Faculty of Medical Science, University of Cuenca. Hospital Vicente Corral Moscoso, Cuenca, Ecuador; ${ }^{3}$ Department of Microbiology, Tumor and Cell Biology (MTC), Karolinska University Hospital, Stockholm, Sweden

Background and Aims Neonatal infections caused by Extendedspectrum beta-lactamase (ESBL)-producing bacteria are associated with increased morbidity and mortality. No data are available on neonatal colonization with ESBL-producing bacteria in Ecuador. The study aimed to assess the proportion of intestinal colonization with ESBL-producing Enterobacteriacae and their resistance pattern among infants hospitalized at the neonatal intensive care unit, Cuenca, Ecuador.

Methods From February to April 2011, stool specimens were collected, every two weeks, from all hospitalized neonates. Rectal swabs were plated on Mac Conkey agar containing cefotaxime and ceftazidime. Species identification and susceptibility tests were confirmed with Vitek2 and the epidemiologic typing was performed using Diversilab (Both bioMérieux).

Results 137 specimens were collected from 78 patients and $61.5 \%$ of the neonates became colonized with ESBL. The majority of the strains were Escherichia coli (EC, 88.5\%) followed by Klebsiella pneumoniae (KP, 11.5\%). Gentamicin resistance occurred in $98.6 \%$ of the EC and $100 \%$ of the KP and ciprofloxacin resistance in $98.6 \%$ of the $\mathrm{EC}$ and $0 \%$ of the KP strains. All strains were susceptible to carbapenems. Epidemiologic typing divided the EC isolates in two clusters and one unique isolate and the KP isolates were divided in two clusters. All EC and KP had bla $a_{\text {СтХ-м }}$ group 1 except for the unique EC isolate that had bla $a_{\text {CTX-M }}$ group 9.

Conclusions The high proportion of patients colonized with four clones of ESBL-producing bacteria, reinforces the necessity for implementing surveillance programs as well as improved infection control to prevent further spread of ESBL strains between hospitalized neonates.

\section{THE VALUE OF PLACENTAL PATHOLOGICAL AND MICROBIOLOGICAL ASPECTS ON PRETERM DELIVERY AND OUTCOME}

doi:10.1136/archdischild-2012-302724.1339

${ }^{1}$ A Korraa, ${ }^{2} Z$ Nabil, ${ }^{3} \mathrm{~N}$ Samir, ${ }^{1} E$ El Geriany. ${ }^{1}$ Pediatrics; ${ }^{2}$ Microbiology, Faculty of Medicine for Girls, Al Azhar University; ${ }^{3}$ Pathology, Ain Shams University, Cairo, Egypt

Background Both clinical findings and the high incidence of decidual inflammation/infection in placentasare associated with preterm deliveries.

Objectives To find out the relation of histopathology and microbiology findings of the placenta and preterm birth and to document the association of placental changes and neonatal outcome.

Methods and results A comparative, analytical study was carried out on Placentas from 100 mothers, 50 with preterm delivery (case group), and 50 with full term delivery(control group). Pathology of the placentas and PCR to detect bacterial SrDNA were performed for the placentae and neonates. Preterm Placentas showed a significantly higher inflammatory lesions than those of full term placentas, (68\% in preterm versus $4 \%$ in full term). The percentage of bacterial isolation by PCR from preterm placenta was significantly higher than full term placenta ( $75 \%$ vs $22 \%$ ), suggesting that most of unexplained preterm delivery is inflammation and/or infection related. The study demonstrated significant association between placental and neonatal bacterialSrDNA. Our results showed that placental inflammatory lesions were significantly associated with lower gestational age, lower weight and length of preterm neonates. On follow up of the preterm neonates, the percentage of RDS, SGA, BPD and neonatal mortality rate were higher among preterm with placental inflammation/infection than those without.

Conclusion Infection of the placenta is associated strongly with histological chorioamnionitis and preterm birth Placental pathology is very useful in identifying undiagnosed subclinical maternal infection. The percentage of neonatal morbidity and neonatal mortality were higher in cases with positive placental findings for inflammation and infection. 